http://doi.org/10.35784/iapgos.2562

\title{
THE TRAINING APPLICATION BASED ON VR INTERACTION SCENARIOS - WITH EXAMPLES FOR LOGISTICS
}

\author{
Wojciech Wlodyka, Dariusz Bober \\ University of Rzeszów, College of Natural Sciences, Department of Computer Science, Rzeszów, Poland
}

Abstract. The main goal of the article is to share some experimental view onto VR training applications, that allows for adaptation of the directed training scenario to a user being trained. The resulted application allows to the three scenarios being selected in any combination of ones, as well as the tasks modification through the input files, before a test starts. The program was developed in the Unity engine, using the modern UnityXR framework providing extensive support for leading virtual reality hardware. The resulting solution presents the possibility of an efficient training in Virtual Reality while modifying the course of training without any needs to recompile the program, and also it shows some positive values of using VR technology as a didactic solution.

Keywords: virtual reality, industrial training, learning systems, logistics

\section{APLIKACJA SZKOLENIOWA OPARTA NA SCENARIUSZACH INTERAKCJI VR - NA PRZYKLADACH DLA LOGISTYKI}

\begin{abstract}
Streszczenie. Głównym celem artykułu jest podzielenie się eksperymentalnym spojrzeniem na aplikacje treningowe VR, które pozwalaja na dostosowanie scenariusza szkolenia ukierunkowanego do szkolonego użytkownika. Powstała aplikacja pozwala na wybór trzech scenariuszy w dowolnej kombinacji, a także modyfikacje zadań poprzez pliki wejściowe, przed rozpoczęciem testu. Program zostat opracowany w silniku Unity, z wykorzystaniem nowoczesnego frameworka UnityXR zapewniającego szerokie wsparcie dla wiodącego sprzętu wirtualnej rzeczywistości. Uzyskane rozwiązanie przedstawia możliwość efektywnego szkolenia z Wirtualnej Rzeczywistości przy jednoczesnej modyfikacji przebiegu szkolenia bez konieczności rekompilacji programu, a także pokazuje pozytywne walory wykorzystania technologii VR jako rozwiąania dydaktycznego.
\end{abstract}

Słowa kluczowe: rzeczywistość wirtualna, szkolenia przemysłowe, systemy edukacyjne, logistyka

\section{Introduction}

Along with the development of augmented and virtual reality technologies, the scope of such applications is increasing significantly. Over the last two decades, many times, scientists have considered the use of this technology, for example in the fields of medicine (neurosurgery and anatomy) [7] and architecture [10].

However, only with the popularization and wider availability of VR's equipment, these solutions begin to penetrate into many industries, and also they are used in a wider spectrum of fields. We come to the point where the use of such VR solutions is even sometimes cheaper and much more attractive, than classic methods based on natural interaction with physical objects, especially in a dangerous environments.

Virtual Reality is no longer a solution for a narrow group of recipients, now it has become a competitive tool for teaching, entertainment and commercial purposes.

The authors of this article have pointed that many of the observed VR applications of training present one, predetermined course scenario. The authors formulate a hypothesis that, it is justified and possible to develop multi-variant applications, in which ones the interaction scenario will be adjusted individually to the needs of a given actor.

The assumption is, by using the indicated tools it is possible to develop a multi-variant training application in VR environment. The selected area for developing application will be a concern on a training course of an employee applying to work in a logistics warehouse. The three flexible scenarios will be implemented as examples.

\section{Evolution of VR technology}

The concept of Virtual Reality is not a new idea - the beginning of a commercial application of this technology is dated to the 90s of the last century [4], when the first commercial devices of this type has appeared. At the beginning, those applications were used only as entertainment devices, but even then it had been noticed the potential of this medium in other areas. Virtual Reality offers something that other medium can't guarantee - a transfer directly into the middle of a displayed environment, and more a seminatural interaction with the displayed objects, by using controllers. This advantage had becomes a very immersive experience for an actor's senses.
However, after the first enthusiastic pilots, commercial success originally VR did not succeed, because the communing environment was uncomfortable, unrealistic, very expensive and required computing power that was unavailable at that time it was too early.

The situation has been changed in the last 10 years, and many of the initial problems of this technology have been resolved, with the fact of the information technology grows up. The current market of such devices, e.g.: Oculus Quest \& Rift [4], HTC Vive, Valve Index, Google Cardboard [14], offers an open architecture for developers, and as results VR becomes available to a wide audience of consumers. The open architecture of the equipment supports easier production of VR applications, and it allows for quick popularization of this type of solutions.

\section{VR in education}

The knowledge transfer is a condition for the progress of civilization, therefore any innovations being used in acquiring education are the catalyst for the development of human beings in general. The educational domain development has a positive impact on a range and methods of providing information [8].

In the digitization era, Virtual Reality has become a medium that can be used in many ways, and in particular it is another logical step in the computers use for educational purposes - the spectrum of possible applications is wide $[1,16]$. No other medium will achieve such a level of immersion and contact with the virtual world as VR is.

One of the biggest problems in education being based on the traditional information lecture is the student involvement for a long process of teaching. Lack of students' commitment leads to: - problems with the knowledge acquisition,

- poor interests of the topic,

- lower efficiency of teaching process, and in consequence it results in negative experiences and even the lack of any tangible learning outcomes.

Each didactic tool that allows for more extensive contact with the topic being taught makes scholars more involved into the process and they are more willing to analyse an issue, an generally it results onto positive effects of they own knowledge increase. In this area the Virtual Reality enables a practical and extended contact with an issue, the internal interaction with virtual displayed objects in VR's applications is intuitive, and students are 
willing to contact within virtual representation of a teaching challenge, due to its modern and attractive looks, and the relatively short period of its presence on the market. Therefore VR teaching applications strengthens students' involvement, allowing the next perspective of education to achieve the next level of sense interaction, just like in video games [2, 3].

\subsection{Distance learning, visualization of complex environments}

The traditional form of teaching, based on direct contact between students and the master, in many situations turns out to be insufficient or even impossible to be implemented. The bright example of such situation are the recent months, when due to the epidemiological situation around the world, almost all teaching activities had to be transferred into online platforms; but also as well before the pandemic there had been many cases where the availability of individual specialists' knowledge push the student's to leave their homes/cites and goes even out of the countries.

Virtual Reality allows us to move wherever we want, as well as interact with other users, if only the application was designed in this way. This adds variety of possibilities to the distance learning experience that can be realized even with a simple smartphone help for each students.

The weaknesses of the traditional didactic form also manifest themselves if the environment in which the examiners have be trained turns out to be dangerous, or it would even endanger the students' lives, and sometimes also if the training costs have no positive economic returns. The organization of educational courses, where the subject of which would be, for example: saving miners from a collapsed mine or utilization of life-threatening materials is practically impossible to implement in their real conditions - of course if such situation happens - the services guards have to show their own experience and in fact they increase their own experience to. But how about the first job, the first mission - when any work in such a difficult environment is practically impossible without exercise beforehand, or in the simplest case it is very expensive and risky for the trainee himself For Virtual Reality these limitations do not exist, and the form of realization and customisation of a given environment depends only on the creators of a given virtual space. Currently, an extensive field in which VR is widely used is medicine operations and procedures in which there is no agreement for the slightest error can be practiced and repeated many times using the Virtual Reality, and in this way prepare the future doctors for real operations [6].

\subsection{Examples of mono-scenario VR teaching applications}

In 2019, the Central Mining Institute has implemented the project titled "Specialized competences of the graduates as a chance for employment in the construction industry on the cross-border labour market". This project has assumed preparation and delivery of a virtual reality workshop, where the aim of it was to train users in the removal of hazardous materials by following the scenarios presented to them via a network connection. The application made it possible to gain practical experience in the removal of life-threatening materials (asbestos) without physical contact with them. The advantage of the application was the possibility of conducting training with two users at the same time through a network connection, which allows for training more people at the same time, and also prepares trainees for cooperation. The examiners were supervised by an administrator who could run scenarios, watch users' actions, as well as indicate errors or give commands on a separate computer. The workshop prepared in that project was mobile and could be assembled and set up anywhere. One of the authors of the current article has had the pleasure to participate in developing process of the above solution.
The limitation of that solution was the lack of the possibility of external interference with in the course of the scenario. The administrator could not change the characteristics of the items/tasks used by the trainees, which limits the functionality of the application. Anyway, this implementation is still actively used for user training $[11,12]$.

Another implementation that allows for only one scenario of interaction is the "Mission: ISS" application available from the Oculus Store [13]. It is an entertainment application that allows an user to play the role of a crew member of the International Space Station and explore its interior. However, the authors of the "Mission: ISS" went a step further than only an entertainment, and they faithfully have reproduced each element of the station, so they give the user a virtual document in which the former station members during a virtual tour tell about everyday life at the space station, describing its important elements, and also drawing the user's attention onto how their life looks like in the space. The application is free and available to anyone with the appropriate equipment. Thanks to this solution, the player is able to move to a place practically inaccessible to him, directly from his room, and thanks to the appropriate preparation of the application by the creators, he can gain knowledge from this experience that may seem boring. A virtual journey to such an exotic place, practically inaccessible to the common student, makes the experience extremely attractive, sharpens the senses and engages the participant to "absorb knowledge" somehow by the way. The disadvantage of the application is its linear structure and relatively small amount of content. After exploring once, the user may not be prompted to return to this application. The game may cause discomfort for some users, because no mechanics were used to increase the quality of the experience [5].

These two advantage applications shows, that even very realistic and attractive visualisation or even very important train course to be passed does not make an user to return back to the VR if it offers only one possible scenario of interactions. At least an user will be bored or will know the scenario as well that he/she will pass the exam without considering the current course. The authors assume that there is necessity to implement multi-scenario interaction with a VR teaching application, and such experiment will be described in the next chapters.

\section{Multi-scenario VR application for logistics}

The logistic warehouses are the space where many people starts their first job. At the first look young man doesn't need to high competitions to work physically there, but in this area there are many dangerousness as for the workers as well for the products being stored there. In this chapter there are described three typical situations which should be tested for warehouse workers' applicants, as in the examples: products confection; personal protective clothes use; safe path.

\subsection{VR mechanic of products confection test}

The first task for the player is to proper stack boxes onto appropriate pallets within a specified time and according to an order. Here any mistakes could results with wrong customers orders confection and future reclamations or could results in the products damage if the boxes will not be fitted correctly.

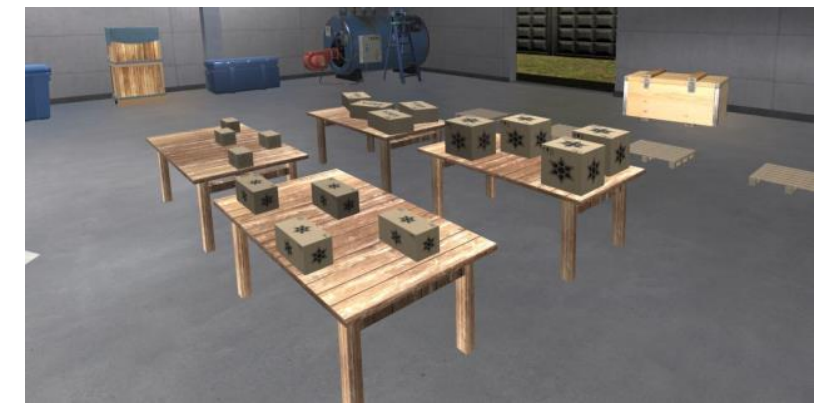


The task itself does not have to consist of a fixed number of pallets, as an example, there are used 16 different boxes palettes and 4 pallets (see Fig. 1). The application is designed in a way that allows the developer to adapt the number of variables to a given variant of the task - it requires recompilation of the program, but it is enough to use the prepared development tools (described in subchapter 3.5) - it does not require interference with the source code of the application itself.

After the task start, the student "physically" grabs the boxes and moves them to the appropriate pallet, he use two controllers (see Fig. 7). When the box is on the appropriate pallet and it is stable (i.e. standing still), he can starts to load the next one. After the proper boxes arranging on a given pallet, the VR mechanic will show him the correct completion of the task by sublighting the pallet in green (see Fig. 2).

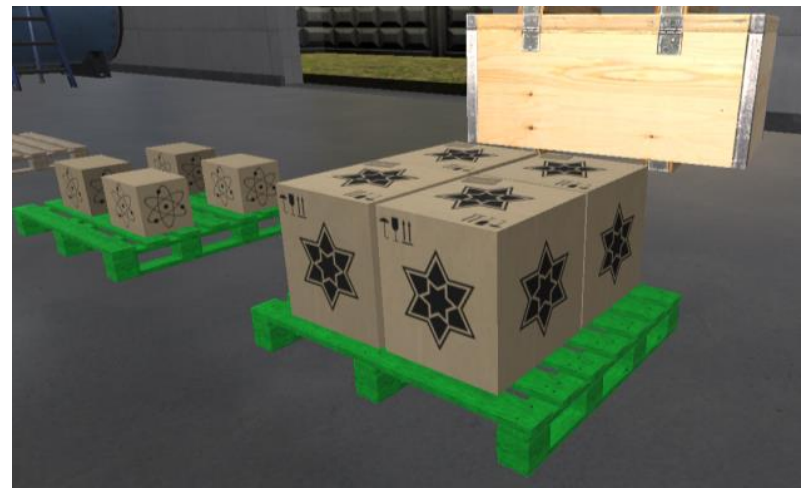

Fig. 2. The proper result of a task [source: own]

If, after placing some boxes on a pallet, it still shows red colour, it means that the student has done a mistake and must correct it. Some typical problems which could happen: objects protruding too much beyond the perimeter of the pallet, inappropriate items are put on the pallet or careless positioning of the item itself. In each case, the student have to correct his mistake by approaching the pallet and moving the boxes to the appropriate places.

\subsection{VR mechanic of protective gloves test}

The second type of mechanics which could be added to the scenario is the task in which a student has to choose the appropriate gloves for cleaning the workplace. There are sharp objects there - broken glass, so before starting work, he has to choose the right protective gloves for this task.

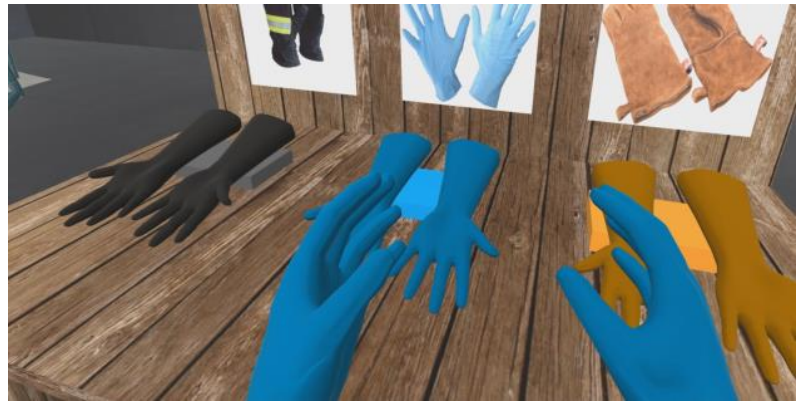

Fig. 3. The appropriate gloves used to a cleaning test [source: own]

Out of the 3 types of gloves, two are correct, but only one type is provided in the workplace (e.g. the leather gloves are correct and available, rubber ones are available too but not correct, the firefighting gloves are safe and available, but they are a specialized equipment for special use and the worker shouldn't use it for casual work).

In this mechanics, the user's prior preparation for training is tested and he will pass the test after the correct choice. Gloves are represented by the appropriate material being put on the student's hands in contact with the prepared objects (see Fig. 3).

\subsection{VR mechanic of safe path test}

The third type of mechanics which could be added to the scenario is a passive mechanics, where a student has to remember about his own safety. This mechanic continues from the test beginning to its end, and the user has to keep careful and remember about necessity of the safety path, because at the same warehouse there are many forklifts and the workers cannot walk everywhere - it is too dangerous. If the mechanic is added to the test, the task consists of paths / communication routes that are used by forklifts to move the loads. The safety paths are marked by thin white stripes in the places where the examiner's entry is safe and withe the wide ones in the places where his move means an error (see Fig. 4)

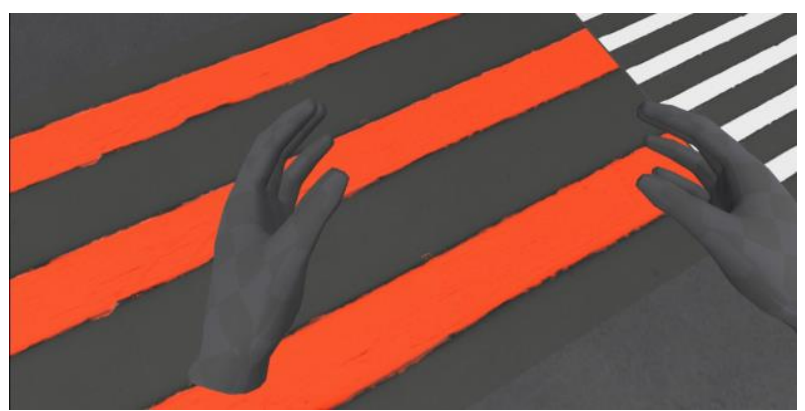

Fig. 4. The wrong cross of a forklift communication path [source: own]

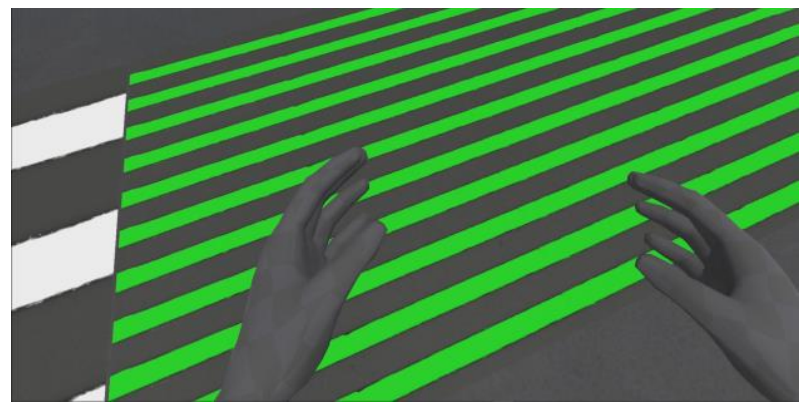

Fig. 5. The proper cross of a forklift communication path [source: own]

Those crosses of communication routes are usually marked and the operators of forklifts are required to increase vigilance in these places - so it is more safe to walk there, than in another places, were the drivers go more fast. If a student enters the wrong area - the place he has violated will immediately turn red to inform him about the error made. Similarly, when he enter the correct area - this will be highlighted in green, to inform him about the correct place of passage (see Fig. 5). Such visual anchors allow the user to get used to similar places in reality of a physical warehouse - a student after the training will remember that the densely placed strips are for his safety, and other belts - for vehicles located in the warehouse.

\subsection{Multi-selection panel}

The user is the entity that has the closest contact with the application - he puts the equipment on his head and manipulates virtual objects by performing specific activities.

The above tasks have been designed to be put into scenarios as full competition testing or as well in an individual selected parts for a dedicated user. The all prepared mechanics could be switched on or off on the main panel of the application (see Fig 6). The user is the entity that has the closest contact with the application - he puts the VR equipment on his head and manipulates virtual objects by performing specific activities. The mechanics are prepared to simulate some real situations in which the employee is supposed to demonstrate perceptiveness, orientation in the field in order to maintain safety, or select the appropriate tool for a given task. 


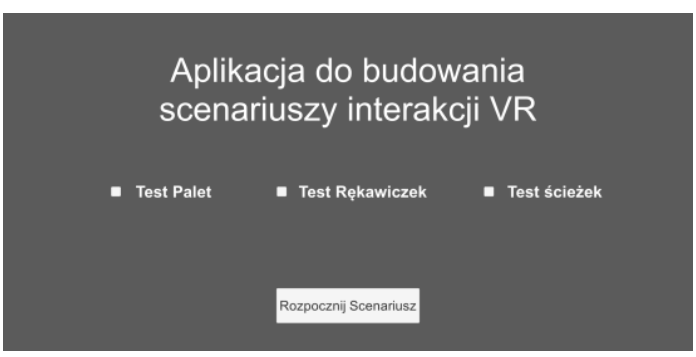

Fig. 6. The main panel layout [source: own]

That an administrator/examiner decides which ones should be passed by the tested user.

\subsection{Software and technological background}

The equipment for which the application has been designed is a modern and up-to-date Virtual Reality Oculus Quest [14] goggles. They are equipped with two controllers, a head set and a cable connecting the equipment to the computer (see fig. 7).

The native operating environment of this model of goggles are the internal peripherals of the device itself (built-in components that allow you to run the application without the need for any external hardware), but thanks to the Oculus Link technology [15] In the case of cable connection with a computer, the goggles can use its computing power to more advanced applications. The prepared solution assumes the use of this option.

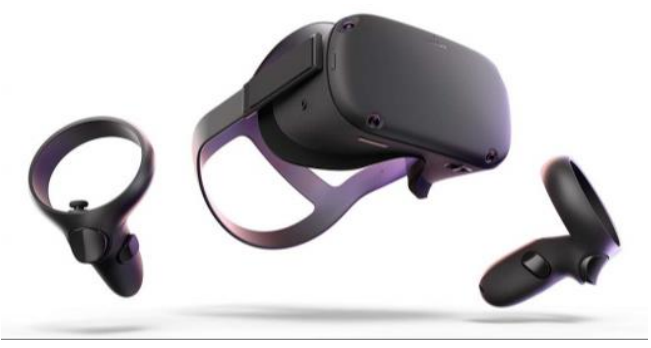

Fig. 7. Oculus layout [source: www.oculus.com]

The solution was made using the modern UnityXR framework, allowing the program to be compiled on any VR device without the need to adapt it to hardware differences

\section{References}

[1] Çankaya S.: Use of VR Headsets in Education: A Systematic Review Study. Journal of Educational Technology and Online Learning 2(1)/2019, 74-88.

[2] Delialioglu O.: Student Engagement in Blended Learning Environments with Lecture-Based and Problem-Based Instructional Approaches. Educational Technology \& Society 15(3)/2012, 310-322.

[3] Hu-Au E., Lee J.: Virtual reality in education: a tool for learning in the experience age. International Journal of Innovation in Education 4(4), 2017.

[4] Kent S.: The Ultimate History of Video Games: The Story Behind the Craze that Touched our Lives and Changed the World. Random House, 2001.

[5] Norouzi N., Bruder G., Welch G.: Assessing vignetting as a means to reduce VR sickness during amplified head rotations. Proceedings of the 15th ACM Symposium on Applied Perception (SAP'18) 19/2018, 1-8.

[6] Riener R., Harders M.: Virtual Reality in Medicine. Springer, London 2012

[7] Satava R. M.: Virtual reality, telesurgery, and the new world order of medicine. Journal of Image Guided Surgery 1(1)/1995, 12-16.

[8] Skibska J., Wojciechowska J.: Współczesna edukacja. Wielopłaszczyznowość zadan. Wydawnictwo LIBRON, Kraków 2016.

[9] Steinicke F.: Being Really Virtual. Immersive Natives and the Future of Virtua Reality. Springer, 2016

[10] Vorländera M., Schrödera D., Pelzera S., Wefersaa F.: Virtual reality for architectural acoustics. Journal of Building Performance Simulation 8(1), 15-25.

[11] https://www.gig.eu/pl/newsy/spotkanie-otwierajace-projekt-pt-specjalistycznekompetencje-absolwentow-szansa-na (available: 10.01.2020).

[12] https://www.gig.eu/pl/przetargi/aktualne/przygotowanie-i-dostarczeniepracowni-wirtualnej-rzeczywistosci (available: 10.01.2020)

[13] https://www.oculus.com/quest/features/ (available: 21.01.2021)

[14] https://arvr.google.com/cardboard/ (available: 11.01.2021).

[15] https://www.pocket-lint.com/ar-vr/news/oculus-rift/153723-what-is-oculus-linkand-how-do-you-use-it (available: 11.09.2020).

[16] https://xd.adobe.com/ideas/principles/emerging-technology/virtual-reality-willchange-learn-teach/ (available: 19.08.2020). between platforms. It is a relatively new solution that significantly unifies the way of creating similar applications between different platforms (the way actions are performed on controllers, traffic recognition, etc.). As a result, the process of creating applications for various VR platforms has been significantly simplified, because it is not necessary to spend a lot of time adjusting the solution to the equipment of different manufacturers.

The engine that was used to build and compile the program is Unity, a complete and supported for years solution for creating games, commercial and educational programs, as well as animations. The engine version that was used to build the solution is 2019.4.1f1, but thanks to the use of UnityXR, which is a built-in tool in the engine, it is possible to update the compiler version.

The code editor that was used to build the solution is Visual Studio Community 2019, a common and proven solution that can be natively connected to Unity, allowing for efficient work and code debugging. The mechanics and the entire software logic have been written in $\mathrm{C \#}$, which is a standard solution when working with the Unity engine.

\section{Conclusions}

The 3D scenes prepared in the presented VR training application are not such effective as e.g. presented in the Mission: ISS application, but that wasn't the main goal of the authors. Using simple graphics we attempt to prove the hypothesis that the multivariant interaction of a user with the virtual world is useful. In the article we describe the sample VR training application for a logistics warehouse worker.

To create a dedicated training scenario in the Unity environment, it does not relay only on the layer of manipulation of windows in this environment. In order to be able to navigate through the previously developed multi-variant scenarios, it is necessary to prepare a script that activates individual scenarios. Such scripts being prepared properly in $\mathrm{C} \#$ can be added to any element visible on the stage, regardless of whether it is a graphic object, UI part or even an empty GameObject, and give them the characteristics that have been defined through the code.

Thus, it has been shown that the user's interaction with the virtual world can be personalized to the needs of a given training scenario, ant it would be more useful than repeats the same activities over and over again. The assumptions of the authors' work were achieved and the hypothesis has been proved.

Eng. Wojciech Włodyka
e-mail: wlodykawojciech@gmail.com

Engineer at the University of Rzeszów, Enthusiast of Virtual Reality and information technologies.

http://orcid.org/0000-0002-8015-9657

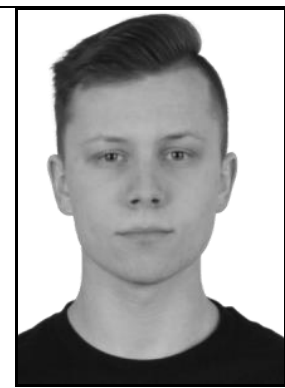

\section{Ph.D. Eng. Dariusz Bobe}

Assistant professor at University of Rzeszów, Department of Computer Science, specialis in databases, industrial system, logistics and electrica power management. The creator of three patents and the Power Modes methodology of energy management

http://orcid.org/0000-0002-0480-700X

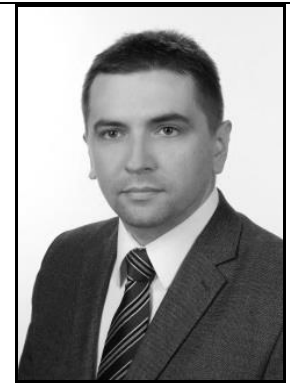

otrzymano/received: 21.02 .2021

przyjęto do druku/accepted: 15.03 .2021 